\section{El punto ciego. \\ Antología de la Poesía Visual Argentina de $7000 a C$ al tercer milenio}

Fabio Doctorovich, Carlos

Estévez y Jorge Perednik

San Diego: SDSU Press, 2016

\section{Un punto ciego vigo-roso}

Ornela Barisone ${ }^{\bullet}$

Universidad Católica de Santa Fe -

Universidad Autónoma de Entre Ríos

\title{
The Blind Man
}

En 1917, Duchamp, junto con dos amigos Henri-Pierre Roché y Beatrice Wood, editaron una revista llamada The Blind Man, como respuesta irónica y polémica al rechazo del «urinario» o la Fountain firmada por Richard Mutt en el Salón de Artistas Independientes. Allí aparecían los argumentos referidos al del «buen gusto» y contra el objeto industrial que pretendían desplazar el objeto contextualizado como readymade en un Salon en el que todas las obras serían aceptadas. Esta revista sirvió como instrumento para que, finalmente, el urinario se expusiera y fuese fotografiado por Alfred Stieglitz con un nuevo contexto: esta vez el de la pintura The Warriors, de Marsden Hartley (1913).

El hombre ciego era aquel que, enceguecido con la luz del arte renacentista y los postulados del ensayo de Alberti Della pintura, no podía aceptar que un urinario ingresase siquiera al Salon a comienzos del siglo XX. Esto nos lleva a interrogarnos por los contextos de producción, circulación y recepción de las artes; en este caso, los que incluyen al objeto poesía visual.

Traigo a colación esta anécdota y el gesto duchampiano para ubicar la tradición de la poesía visual en una ceguera académica que conservó, por diferentes razones, a la poesía discursiva como su brillante más preciado. La poesía visual en Argentina fue colocada en un «lugar maldito», porque predominó la «separación entre los signos lingüísticos y literarios y los visuales y plásticos» (Aguilar, 2006: 9)² y ocupó el espacio de lo lúdico «en una literatura nacional que por lo general estaba muy cargada de sentido y de intelecto, y estaba tan volcada a lo discursivo y a las ideas» (9).

Un efecto de ese lugar invisibilizado, más no invisible, mucho menos inexistente, le cupo a la poesía visual: es este el punto ciego que presentamos en una Antología compilada por Fabio Doctorovich, Carlos Estévez y el entrañable Jorge Perednik.

Un punto ciego (utilizando la metáfora propuesta por Perednik proveniente de los aportes de 1668 de Edme Mariotte; filósofo y matemático francés) que exhibe la construcción social de la mirada, que es la muestra palmaria de que nuestros ojos perciben una realidad bastante sesgada y que mirar no es lo mismo que ver o, en palabras de John Berger, los modos de ver se actualizan, se activan y recontextualizan dinámicamente.

\footnotetext{
- Doctora en Humanidades y Artes con mención en Literatura por la Universidad Nacional de Rosario, posgraduada en Artes Mediales de la Universidad Nacional de Córdoba y Profesora y Licenciada en Letras por la Universidad Nacional del Litoral. Es docente titular de la Facultad de Filosofía y del Ciclo de Licenciatura en Letras de la Universidad Católica de Santa Fe y de la Universidad Autónoma de Entre Ríos. Su área de investigación incluye poéticas experimentales, poesía visual, relaciones interartísticas, artes comparadas, estudios visuales, arte latinoamericano y argentino de los sesenta, poesía argentina y latinoamericana de mediados de siglo XX.
} 
Una antología que establece un recorte diacrónico desde las cuevas de las manos datadas del $7000 \mathrm{aC}$ en la Patagonia argentina a la poesía digital o las apropiaciones postautónomas en el arte actual. Su existencia es un modo de dar a ver, de reconducir la mirada hacia esas prácticas marginales a fin de pensar una historia de la poesía argentina marginal o en los márgenes, ya que la crítica de arte (fundamentalmente la literaria) y las instituciones culturales relegaron, por ejemplo al invencionismo y a los experimentos poéticos derivados de la poesía visual, priorizando la poesía analítico-discursiva. Perednik avizoró lúcidamente esta vinculación que se integra en esta compilación.

En los años ochenta e inicios de los noventa, paralelamente a la reivindicación del aspecto discursivo de la poesía, se publicaron los números sobre poesía visual

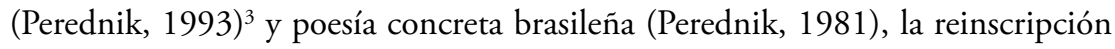
de Edgardo Antonio Vigo como poeta visual en Paralengua, la Othra Poesía ${ }^{4}$ y el homenaje a Oliverio Girondo (Perednik, 1984) en la revista Xul. Signo viejo y signo nuevo (1980-1997), dirigida por Jorge Santiago Perednik. Esta difusión fue central para visibilizar estas prácticas que no formaban parte del establishment.

Pienso cuánto hemos avanzado hoy, al punto, (visible), que estos temas hayan suscitado el interés de organismos que subsidian investigaciones y que la producción de poesía visual pueda ser incorporada en las universidades como lo fue la poesía concreta brasileña en el caso de Brasil. Pienso que, en la formación docente, la poesía visual aparece como una herramienta potente y vigo(rosa) de trabajo interdisciplinario; por ejemplo, en un género como el libro-álbum o en una propuesta de taller que vincule las artes visuales y la literatura.

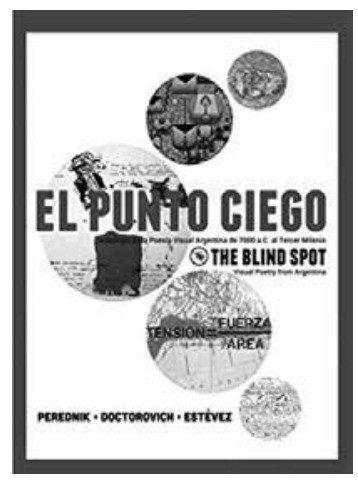

Figura 1. Tapa del libro

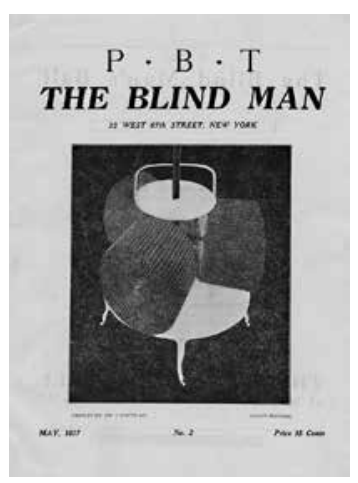

Figura 2. Portada de The Blind Man (1917), N. 2 Mayo, New York.

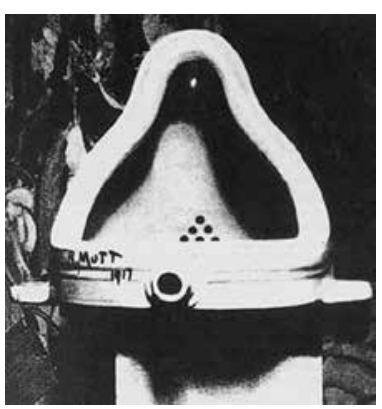

Figura 3. El urinario Fountain de Marcel Duchamp en 1917. Fotografía de Alfred Stieglitz. 
nacionalmente por su labor de archivista apasionado y sus intercambios, aunque desconocida en el propio país.

Asimismo, esta antología completa una de las pretensiones de la Expo Novísima Poesía/69, organizada por Romero Brest y Vigo en el Instituto Torcuato Di Tella de Buenos Aires: dar a conocer aquello que, incluso, para Romero Brest era una tarea audaz y sin precedentes "qué es ahora la poesía». Romero Brest se interrogaba por el sentido actual de la poesía, una pregunta por la especificidad de lo literario que, aunque pareciera demodé, resulta sumamente actual.

El qué es ahora la poesía, si seguimos a Gyndenfeldt $(2008)^{6}$, lo cambiamos por cuándo hay poesía. El pasaje del poema suspendido dentro o fuera del museo (experiencias de la Expo Novísima), las palabras combinándose con fórmulas matemáticas (los poemas matemáticos de Vigo), la ilegibilidad (en Mirtha Dermisache, en León Ferrari), la expulsión de la palabra o su integración en la imagen (Alberto Greco), la inclusión del objeto, la transfiguración de los soportes, la bienvenida a la participación son algunos de los aportes de esta antología para comprender el arte actual.

Esta antología implica un recorte, que es también un volver a ver, un saber recontextualizado que ubica a Vigo y a Diagonal Cero en un punto álgido. Vigo, desde ese punto ciego (un vacío negro, lo ilimitado, lo sublime), nos convoca a la vigo(ros)idad rosa/roja. Un tinte de color para pintar imaginariamente los ojos de los blind man.

\section{Notas}

${ }^{1}$ Texto leído en la presentación del libro, realizada en la Biblioteca Nacional de Buenos Aires el 11 de noviembre de 2016.

${ }^{2}$ Aguilar, Gonzalo (2006): «El laberinto sin secreto». Poesía visual argentina. Ed. Fernando G. Delgado y Juan C. Romero. Buenos Aires: Vórtice. pp. 9-11.

${ }^{3}$ Este número incluyó el siguiente índice: Poesía visual del siglo XVIII - Vigo - Paralengua - Duchamp - El Oulipo - Queneau - Perec - Roubaud - 12 visuales argentinos: Ayrau, Castro, Cignoni, Doctorovich, Escobar, Estévez, Gal, García, Lépore, Perednik, Rösleer, Sheines. El consejo editor estuvo a cargo de Roberto Cignoni y Jorge Perednik, la ilustración de tapa a cargo del Equipo Xul y, como editor, Perednik.

${ }^{4}$ Grupo argentino conformado en 1989 por Roberto Castro, Roberto Cignoni, Fabio Doctorovich y Carlos Estévez. Éste último afirmó que «la ampliación del concepto de lo poético, la redefinición de su especificidad, la corporeidad poética, la disolución de los límites entre la poesía y las restantes disciplinas artísticas, son algunas de las cuestiones que se derivan de las premisas. En síntesis, Paralengua posee un carácter tentacular y proteico al cual no debe retaceársele lo desprejuiciado, lo festivo, lo intelectual, lo sensitivo y, primordialmente, la pasión con que se apropia de todas las dimensiones de la palabra».

${ }^{5}$ Retomo esta expresión y el juego de palabras de Jorge Perednik, en alusión a Vigo.

${ }^{6}$ Gyndenfeldt, Oscar: «¿Cuándo hay arte?» en Oliveras, Elena (ed.): Cuestiones del arte contemporáneo. Hacia un nuevo espectador del siglo xx. Buenos Aires: Emecé, 2008. 